\title{
Pollen Grains Cytology of Wheat Triticum aestivum L.
}

\author{
Azhar K. Hamdi and Atef S. Soliman \\ Biology Department, College of Science, Baghdad University, Baghdad, Iraq \\ Received April 11, 1977 \\ Study of wheat pollen grains cytology may reveal the interesting correlation \\ between pollen cytology and the shortage in their viability and the inability to be \\ stored for a long time under normal conditions. \\ Bishop (1949), and Conger and Fairchild (1953) were interested in establishing \\ an improved method of pollen culture for cytological studies. Bennett and Hughes \\ (1972) induced additional mitosis in pollen grains of wheat by the use of 2-chlorethyl \\ phosphonic acid (Ethrel).
}

\section{Materials and methods}

Six hexaploid wheat Triticum aestivum L. cultivars were grown in the field of the College of Science, Baghdad University, Baghdad, Iraq. The cultivars were: Pitic 62, Sonora 64, and Lerma Rojo (Mexican cultivars); Saber Beg, Ageeba (Iraqi cultivars) and Giza-155 (an Egyptian cultivars).

The six cultivars were planted randomly in three randomized complete blocks on November 10, 1975. They were treated agronomically as usual in regard to irrigation, addition of fertilizers and weed control.

For studying pollen cytology the procedure of Jagathesan and Sreenivasan (1966) was modified to fit wheat pollen grains. The complete procedure used was as follows:

1. Ripe anthers were collected at anthesis time and were treated with $0.2 \%$ colchicine solution in a small vial for $1 \mathrm{hr}$ at $26-28^{\circ} \mathrm{C}$.

2. Anthers were washed in water 2-4 minutes and then treated with a solution of $0.002 \mathrm{M}$ hydroxyquinoline for $1 \mathrm{hr}$ at $26-28^{\circ} \mathrm{C}$ and they were washed in water for 10 minutes.

3. Anthers were fixed for 24 hours in Östergren and Heneen's solution that was composed of methanol $60 \mathrm{ml}$, chloroform $30 \mathrm{ml}$, distilled water $20 \mathrm{ml}$, picric acid $1 \mathrm{gm}$ and mercuric chloride $1 \mathrm{gm}$. At the end of fixation period the material was stored for a period up to $6-8$ weeks in $70 \%$ methyl alcohol in a refrigerator.

4. The anthers were hydrated in $70 \%$ and $35 \%$ methyl alcohol then washed by distilled water.

5. The anthers were hydrolyzed in $1 \mathrm{~N} \mathrm{HCl}$ for 20 minutes then washed in water.

6. The anthers were stained in leuco-basic fuchsin (Schiff's reagent) for 30-60 minutes.

7. The anthers were smeared into a drop of aceto-carmine stain and gently heated.

8. A cover glass was placed on the top of the material and gently tapped by 
keeping the slide between folds of a filter paper and were given uniform pressure to prevent the formation of fissures in pollen grain wall.

9. The cover slip was sealed with wax for longer study under the microscope.

10. For permanent preparations the sealed slides were stored in the refrigerator for $1 / 2$ hour.

11. The wax was removed by a needle and the slide was immersed in a mixture of glacial acetic acid and n-butyl alcohol 1:1 to remove the cover glass.

12. The slide was transferred to n-butyl alcohol for two changes. The slides were kept for about two minutes in each change.

13. Canada balsam was used for mounting to get a permanent preparation.

Table 1. Average percentage of abnormal pollen grains (mononucleate, binucleate, abnormal trinucleate, and tetranucleate) among the six cultivars of wheat

\begin{tabular}{ccccccc}
\hline & \multicolumn{6}{c}{ Cultivars } \\
\cline { 2 - 7 } Replicate & Pitic-62 & Sonora-64 & Saber Beg & Lerma Rojo & Ageeba & Giza-155 \\
\hline 1 & 1 & 13 & 3 & 1 & 2 & 3 \\
2 & 3 & 10 & 0 & 1 & 4 & 2 \\
3 & 2 & 10 & 0 & 2 & 5 & 2 \\
\hline Total & 6 & 33 & 3 & 4 & 11 & 7 \\
\hline Average & 2 & 11 & 1 & 1.33 & 3.67 & 2.33 \\
\hline
\end{tabular}

Each figure in Table 1 equals the mean of abnormal pollen of five samples from each block.

Table 2. Analysis of varience for the percentage of abnormal pollen grains in the six cultivars

\begin{tabular}{lccc}
\hline \multicolumn{1}{c}{ Source } & d.f. & M.S. & F \\
\hline Cultivars & 5 & 42.5 & $22.14^{* *}$ \\
Blocks & 2 & 0.4 & $0.21 \mathrm{~ns}$ \\
Error & 10 & 1.92 & - \\
\hline
\end{tabular}

** Highly significant at 0.01 level.

ns Not significant at 0.05 level.

\section{Experimental results}

The percentage of abnormal pollen grains in each of the six cultivars were counted from five random samples of the three replicates. Table 1 shows the average percentage of abnormal pollen grains for each cultivar. There was a highly significant difference between the six cultivars as shown from the analysis of varience (Table 2).

Figs. 1-7. 1, mature trinucleate pollen grain of the cultivar Pitic 62. 2, mononucleate pollen grain from the cultivar Pitic 62. 3, binucleate pollen grain from the cultivar Ageeba. 4, binucleate pollen grain from the cultivar Sonora 64 , one of the nuclei is deviding asynchronously. 5 , trinucleate pollen grain from the cultivar Ageeba showing extra division in one of the nuclei. 6 , abnormal trinucleate pollen grain from the cultivar Sonora 64 . The nuclei are different in shape from the normal pollen grain. 7, tetranucleate pollen grain from the cultivar Saber Beg. 

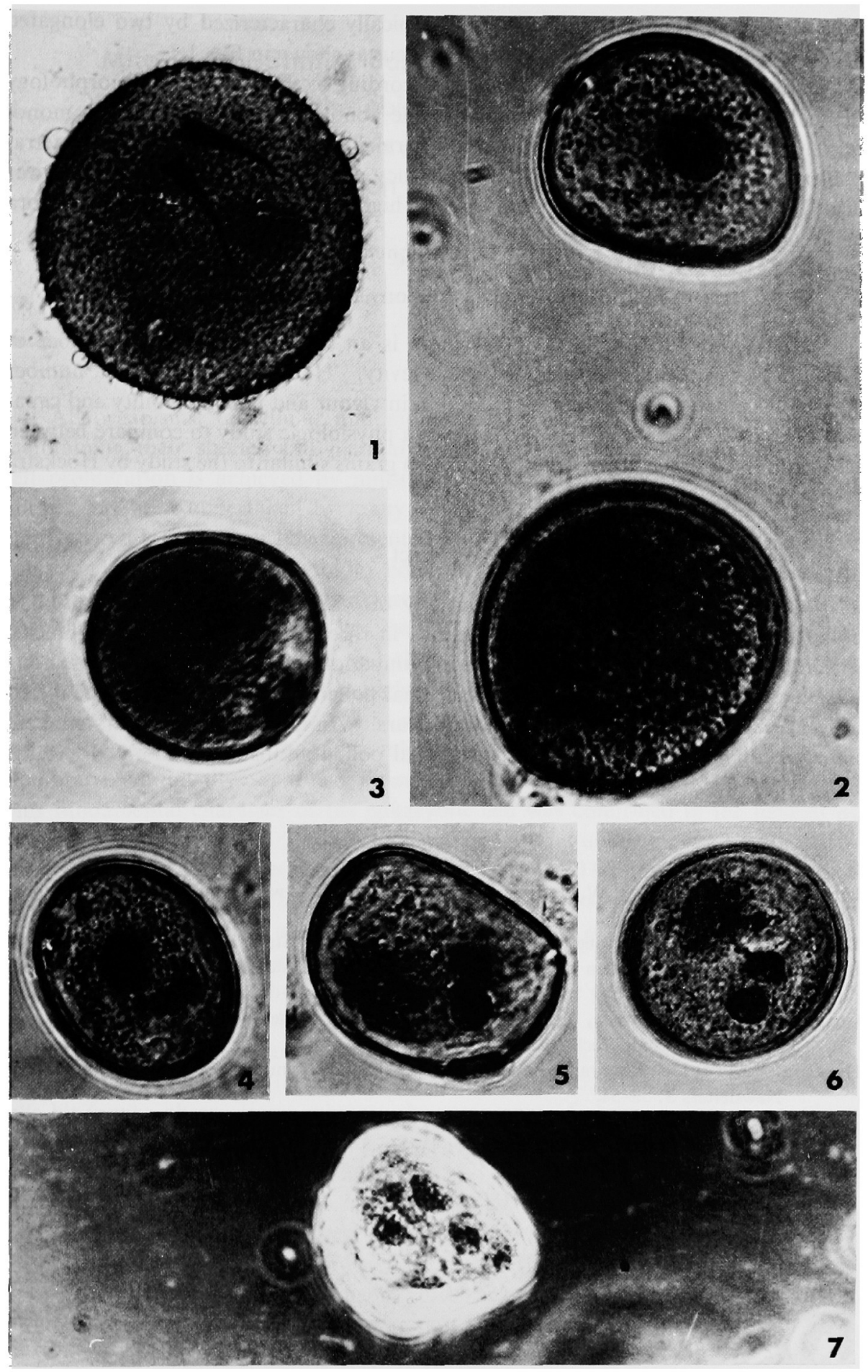
Also the normal pollen grains were typically characterized by two elongated generative nuclei and one oval vegetative nucleus as shown in Fig. 1.

The abnormal pollens were classified according to the number and morphology of nuclei in the mature pollen. Some of the abnormal pollen grains were mononucleate (Fig. 2), binucleate (Figs. 3, 4), abnormal trinucleate (Figs. 5, 6), and tetranucleate (Fig. 7) pollen grains. The frequency of the abnormal pollen grains was least in the Iraqi cultivar Saber Beg and was highest in the Mexican cultivar Sonora 64.

\section{Discussion}

Brewbaker (1957) suggested that there is an association between number of nuclei in pollen grains and pollen grain longevity. However we found that number of nuclei is closely associated with reduction in vigour and pollen viability and capacity to be stored for a long time. However a physiologic study to compare between respiration rate in the different kinds of pollen grains similar to the study by Hoekstra (1973), is needed.

\section{Abstract}

A technique, for studying the cytology of wheat pollen grains, was used to compare between six wheat cultivars grown in three randomized complete blocks. There was found a significant difference in number of abnormal pollen grains among the six cultivars. The percentage of abnormal pollen grains may explain the difference in pollen viability among wheat cultivars. Among the six cultivars studied, Saber Beg had the least number of abnormal pollen grains and Sonora 64 had the highest.

\section{References}

Bennett, M. D. and Hughes, W. G. 1972. Additional mitosis in wheat pollen induced by Ethrel. Nature 240: 566-568.

Bishop, C. J. 1949. Pollen tube culture on a lactose medium. Stain Tech. 24: 9-12.

Brewbaker, J. L. 1957. Pollen cytology and incompatibility systems in plants. J. Hered. 48: $217-277$.

Conger, A. D. and Fairchild, L. M. 1953. A quick freeze method of making smear slide permanent. Stain Techn. 28: 281-283.

Hoekstra, F. A. 1973. Respiration and vitality of bi- and trinucleate pollen incompatibility. Newsletters 3 : 52-54.

Jagathesan, D. and Sreenivasan, T. V. 1966. A pollen grain squash technique for Saccharum and related genera. Stain Techn. 41: 43-47. 